\title{
Retraso o diferencia del arte modernista latinoamericano. Francisco Brugnoli: ¿un arte pop?
}

\author{
Carolina Pavez \\ Universidad de Chile / Conicyt Doctorado 21130135 \\ mcpavez@gmail.com
}

\begin{abstract}
Resumen
El artículo tiene por objetivo develar, a través del examen de algunos textos de teoría del arte latinoamericano, cómo el hecho de adherirnos a pautas consagradas fue modelando la apreciación y reflexión sobre nuestro arte y nosotros mismos; tergiversando, no comprendiendo o, simplemente, acomodando nuestros discursos a fin de ser "modernos". La revisión de la primera propuesta del artista chileno Francisco Brugnoli-catalogada erróneamente como arte pop-será paradigmática para tal finalidad.
\end{abstract}

Palabras clave

Arte latinoamericano, retraso, diferencia, arte pop, Francisco Brugnoli.

\section{Atraso ou diferença da arte modernista latino-americana.} Francisco Brugnoli: uma arte pop?

\section{Resumo}

O artigo pretende revelar, através do exame de alguns textos da teoria da arte latinoamericana, como aderir às diretrizes consagradas foi modelando a apreciação e a reflexão sobre nossa arte e nós mesmos; distorcendo, não compreendendo ou, simplesmente, acomodando nossos discursos para ser "modernos". A revisão da primeira proposta do artista chileno Francisco Brugnoli-erroneamente categorizada como pop art-será paradigmática para esse fim.

\section{Palavras chave}

Arte latino-americana, atraso, diferença, arte pop, Francisco Brugnoli

\section{Delay or difference of Latin American modernist art. Francisco Brugnoli: pop art?}

\begin{abstract}
By examining some theoretical texts on Latin American art, this article aims to reveal how adhering to a rigid framework has shaped our appreciation and reflection on art and on ourselves; distorting, misunderstanding or, simply, accommodating our discourses in order to be "modern." The analysis of Chilean artist Francisco Brugnoli's first work-mistakenly categorized as pop art-serves as a paradigmatic example for this purpose.
\end{abstract}

\section{Keywords}

Latin American art, delay, difference, pop art, Francisco Brugnoli. 
Carolina Pavez. Retraso o diferencia del arte modernista latinoamericano. Francisco Brugnoli: ¿un arte pop? 


\section{Introducción}

Para muchos artistas e intelectuales latinoamericanos, la búsqueda de la modernidad fue una obsesión. Seguramente porque, como dice Octavio Paz, la modernidad artística tomó la forma de una diosa esquiva, como un espejismo que nunca se alcanza (1990). En las artes visuales, esta esquividad pudo deberse a que el impulso de progreso estuvo inclinado a recrear, adaptar, apropiar o traducir productos y operaciones a fin de acoplarse a "lo avanzado" (de turno). Es así como, el academicismo hubo de ser objetado para instalar al impresionismo; el impresionismo, para apostar al cezannismo; el cezannismo, para dar lugar al geometrismo; éste, al informalismo; el informalismo, para introducir el conceptualismo, el pop ... en fin.

La persistencia de este acoplamiento entraña, en parte, la dificultad de sobreponernos a las marcas de la subestima ocasionadas por la jerárquica occidentalidad de la que somos parte. Josetxu Beriain, nos da algunas claves del origen de este fenómeno. Señala que el descubrimiento de nuevas zonas geográficas trajo a la luz una variedad de culturas coexistentes. Esto promovió la urgencia de crear una historia mundial interpretada en términos de "progreso". La cultura dominante, estableció así una comparación de los "niveles culturales", desplazando el progreso espiritual en favor del progreso mundano. De esta manera, se configuraron diferentes ritmos más o menos acelerados de cambio histórico-social, sustentados en significados del tipo metrópoli-colonia, capitalismo-desarrollo, socialismodependencia-revolución. Esta tendencia se aloja en la idea de que todos debemos recorrer y cumplir con una serie determinada de etapas y procesos a fin de ser parte del "progreso". El estigma del atraso, de hecho, acontece cuando se percibe un "desacoplamiento" respecto de las fases, metas y significaciones imaginarias impulsadas por la cultura dominante:

El progreso es una significación imaginaria que es apropiada de forma asimétrica por diferentes colectivos a nivel planetario. Así, la contemporaneidad de los no-contemporáneos ("atrasados", "subdesarrollados", "bárbaros", "salvajes", "primitivos", "paganos") participa, aunque de una forma desigual, del nuevo mito del "progreso" (Beriain, 2005: 20).

En el caso del arte, las fases, metas y significaciones de progreso operaron de la misma forma, lo que tuvo como efecto, como decía antes, el ponernos tras modelos dados a razón de insertarnos en la narrativa de la modernidad artística. En consecuencia, modernizarse representó un gesto de huida frente a todo aquello que expusiese retraso cultural.

Contraproducentemente, las modernizaciones artísticas -entendidas como "puestas al día" ${ }^{-}$fueron operaciones nada más alejadas del espíritu moderno;

1. La modernización artística comprende el proceso que busca hacer que algo -lo artístico- alcance "lo nuevo" o "lo actual", pero adscribiéndose a estrategias, prácticas y teorías oficializadas como 
que fue tal, precisamente, por presentar una subjetividad libre, crítica, reflexiva, siempre nueva y rupturista (Habermas, 1989). Podemos deducir, entonces, que la causa de la esquividad de la modernidad artística pudo originarse a razón de que el acoplamiento a una significación estandarizada contradice irremediablemente su condición.

No obstante lo dicho, y en el otro extremo, la tematización de la pugna contra lo hegemónico no haría más que aseverar el rol del subordinado, reafirmando así la relación de jerarquía. En palabras de Santiago Castro-Gómez:

Desde este punto de vista, las narrativas anticolonialistas, con su juego de oposiciones entre los opresores y los oprimidos, los poderosos y los desposeídos, el centro y la periferia, la civilización y la barbarie, no habrían hecho otra cosa que reforzar el sistema binario de categorizaciones vigente en los aparatos metropolitanos de producción del saber (1998: 173).

Más aún, subrayar un mandato que ya no es opresor (pues dominación y hegemonía no son lo mismo), perpetúa el conflicto. Concedamos pues que contemplar nuestra posición y disposición frente a lo hegemónico no implica determinarnos a partir y/o en contra de ello, ni menos omite la pregunta por nosotros mismos. Generar una toma de consciencia ("darnos cuenta") de la propia responsabilidad de lo que hemos aceptado y construido será la perspectiva a seguir.

En consecuencia, y como hipótesis principal, planteo que la adopción en Latinoamérica ${ }^{2}$ de las fases, metas y significaciones de progreso artístico no sólo hizo más esquiva a la (nuestra) modernidad artística, sino que también modeló nuestra apreciación y reflexión sobre el arte y nosotros mismos, desfigurando o incomprendiendo nuestros propios modernismos ${ }^{3}$. De hecho, esta inclinación se instaló como una suerte de mecanismo estructurador de respuestas -conscientes e inconscientes- ajustadas a las directrices de estas significaciones, sean cuales sean, de generación tras generación, y, peor aún, sin que los agentes culturales se percaten siempre de ello. Es más, emplazó la errónea creencia de que ninguna propuesta artística o teórica se gesta aquí (pues "lo avanzado" siempre está en otra parte); convirtiendo a esta tierra en un lugar infructífero o, en el mejor de los casos, en un territorio sólo apto para el trasplante, la asimilación, la traducción o la adaptación. Por dar un ejemplo, si bien Gerardo Mosquera destaca que el

modernas. Todo lo contrario, los modernismos latinoamericanos, si bien albergan el mismo deseo de actualidad, proponen y renuevan activamente sus prácticas y postulados de acuerdo a sus propias transformaciones históricas, sociales o culturales.

2. En lo personal, subscribo a la actualización que ofrece Ángel Rama de la definición de Latinoamérica y su cohesión regional: "La unidad de América Latina ha sido y sigue siendo un proyecto del equipo intelectual propio, reconocida por un consenso internacional. (...) Por debajo de esa unidad, real en cuanto proyecto, real en cuanto a bases de sustentación, se despliega una interior diversidad que es la definición más precisa del continente" (2008: 67).

3. Entenderemos el término modernismo ampliamente, esto es, según la definición dada por Marshall Berman (2011: 2), a saber, como respuestas artísticas a la luz de las transformaciones y experiencias de la modernidad. 
modernismo brasileño edificó el paradigma de la antropofagia sobre la base de una apropiación crítica, selectiva y metabolizante de las tendencias artísticas europeas, también reconoce que esta noción ha sido manipulada -en parte por el auge de las ideas postmodernas- para explicar, justificar y facilitar la apropiación, la resignificación y la validación de la copia en el contexto de la relación subordinada de Latinoamérica con el Occidente hegemónico. El abuso de la batalla digestiva tiene como consecuencia "la adicción, el estreñimiento o, peor aún, la diarrea" (Mosquera, 2009: 9).

En otros casos, el deseo de alcanzar la modernidad artística hizo -y hace aúnque surgieran innumerables reproches hacia el arte local que, habiendo aspirado a ser moderno, no haya cumplido con los parámetros de progreso del arte euro-estadounidense. Luego, que se levanten halagos y celebraciones cuando nos ajustamos a sus dictados (mejor aún, si lo conseguimos sin desfases históricos). $\mathrm{O}$, como consecuencia, que se hayan invisibilizado o no se hayan comprendido en profundidad la naturaleza particular de nuestros logros modernistas.

Para visibilizar este fenómeno revisaré algunos textos de teoría del arte latinoamericano -en específico, del Cono Sur-relativas a propuestas artísticas anteriores a la (hipotética) posmodernidad artística, de tal forma de apreciar cómo el hecho de adherirnos a las pautas consagradas como modernas fue condicionando nuestras evaluaciones. A través del desarrollo del artículo podremos reconocer algunos de sus efectos: la percepción de atraso, el acomodo a las pautas, el uso del juicio de autoridad, el letargo creativo/intelectual y, finalmente, la incomprensión de nuestros modernismos. Este último punto, visible de forma ejemplar en la categorización de la primera propuesta artística de Francisco Brugnoli como arte pop.

Cabe señalar que la selección variada de propuestas artísticas, autores y fragmentos de textos analizados, busca dar cuenta de la persistente presencia a lo largo del tiempo de estos condicionamientos; incluso presentes en posiciones argumentales aparentemente críticas de la relación del arte latinoamericano respecto a los postulados centrales. Hago, sí, la advertencia de que esta exploración apunta a un problema específico: la tendencia a adoptar -consciente o inconscientemente- las fases, metas y significaciones (imaginarias) del progreso en el arte, por lo que en ningún caso representa al discurso $o$ al arte latinoamericano en su totalidad.

4. Ciertamente el teórico cuestiona la simplificación del modelo "arte latinoamericano apropiacionista" para resaltar la variedad de la producción simbólica en el continente. Afirma que los artistas de hoy, en lugar de apropiarse de la cultura hegemónica para transformarla en beneficio propio, están proponiendo obras desde sus propios contextos y reacciones personales y subjetivas, sin complejo alguno, pero estando bien informados sobre el arte internacional y su lenguaje (Mosquera: 2009). No obstante, cabe evaluar si ese "estar bien informados" podría encubrir o no una tendencia igualmente acopladora, ya no a los "movimientos" pero sí a un tipo de lenguaje hegemónico (post-conceptual o post-minimalista, por ejemplo) que operaría como una suerte de membresía para que la propuesta artística logre una inscripción en el arte central actual. 


\section{Atraso, retraso y letargo periférico}

Para dar cuenta de cómo la adhesión a las pautas hegemónicas logra colarse en nuestro conocimiento y apreciaciones sobre nuestro arte, tomaré un caso poco evidente en apariencia, justamente para ilustrar como subyace esta adhesión sin que ni siquiera nos demos cuenta.

Ticio Escobar, crítico de arte y promotor cultural de las especificidades del arte latinoamericano, hace referencia a las tímidas alteraciones impresionistas durante la década de los años diez del siglo XX en Paraguay. Reclama que estas novedades no consiguen una ruptura:

(...) no entran en disputa con el concepto naturalista de la representación, apenas lo dinamizan. Eximida de la obligación de desmontar una tradición académica de la que carecía, la pintura paraguaya no encontraba aún conflicto entre la representación de las Bellas Artes y la figuración modernista (...).

Por lo tanto, el atraso del Paraguay, su dependencia redoblada y su aislamiento van diseñando una modernidad solitaria y diferente, diferida. Los pintores echan mano de sucesivos elementos estilísticos formales no siguiendo los impulsos internos de un proceso necesario sino respondiendo a los requerimientos, retardados siempre, de los tiempos subtropicales. Ni la ruptura con el pasado, ya queda dicho, ni la enunciación de un ideario utópico, ni los alardes de actualización significaban entonces temas de preocupación o motivos de seducción para los artistas premodernos (2004: 13).

En estas palabras se puede apreciar la evaluación que condiciona a la crítica del arte latinoamericano. Primero, se establece implícitamente un nexo asociativo entre la orgánica y necesaria "evolución interna de las formas" con la idea de que, para entrar a la modernidad, todos debemos recorrer y cumplir con una serie de etapas y pautas, cumplir con "un proceso necesario", en este caso de ruptura con el concepto naturalista de la representación. En palabras simples, la evolución interna de las formas, sus problemas y planteamientos, deben responder necesariamente de la misma manera "evolutiva" que el arte hegemónico. Cualquier desviación-como tomar los recursos disponibles para ir en otra dirección-se aprecia como anómala o vacía, ya que no cumple con esa dirección ineludible. En el reproche del teórico paraguayo resuena subterráneamente un mensaje con voces del pasado: Los pintores premodernos paraguayos [los hombres salvajes y primitivos] no pusieron en conflicto la representación de las Bellas Artes tal como lo hicieron los modernos [los civilizados]. Expuesto así, pareciera ser que el cuestionamiento de la representación naturalista debió ser el único camino para emprender una modernidad artística. El problema de esta apreciación es que excluye del todo la posibilidad de configurar un camino específico de realización de la modernidad ${ }^{5}$.

5. Shmuel Eisenstadt (2000) señala que la vieja dicotomía entre sociedades modernas y tradicionales ya no es válida, conforme la mayor parte del mundo se ha vuelto o se está volviendo moderno. Advierte, eso sí, que estas modernidades son diferentes, ya que son producto de complejos encuentros donde se reinterpretan los programas de la modernidad a la luz de las tradiciones, crisis y rupturas de cada 
Si bien es cierto que, para levantar un modernismo, la ruptura, como parte del fuero moderno, es vital, establecer que esa ruptura deba dirigirse hacia una dirección obligatoria es desacertado. Los modernismos son tal, no sólo porque buscan la ruptura de y con la tradición, sino porque viven "la experiencia de rebelarse contra todo lo que es normativo" (Habermas, 1992: 90), incluido los parámetros oficializados como vanguardistas. En otras palabras, se inclinan constantemente a renovar los recursos, a revisar las prácticas y la recepción artística, a la rebeldía, a cierta fe en el progreso, a la búsqueda de una expresión artística propia, a la ruptura y desencanto de las tendencias, a la libertad, al espíritu nuevo, etc. ... por muy distintas vías y formas que esto pueda ser expresado.

Contrariamente a lo que plantea Escobar, la fórmula dada, que fija lo moderno en la letra y no en su espíritu, no nos sirve como vara para medir la modernidad de estas expresiones. Que los pintores paraguayos no hayan seguido la ruta establecida-disolución de la representación- no es algo que se les pueda, en estricto rigor, reprochar. Por lo tanto, esta disparidad, esta "anomalía" en sí misma, no puede ser indicador de atraso. De existir un atraso, un quedarse atrás o un estancamiento, este se habría originado en el carácter de su impulso, es decir, a causa de las "tímidas alteraciones" que propuso la pintura paraguaya de ese tiempo. Escobar advierte este retraimiento, pero establece su reproche dentro del paradigma de una similitud malograda, esto es, amonestando el hecho de no haber alcanzado un proceso parecido al del arte hegemónico (disputa con el concepto naturalista de la representación).

Si distinguimos este desarrollo, podremos advertir que el verdadero origen de la incompetencia moderna de la pintura paraguaya de aquel período, no se gestó por el retardo en el seguimiento de las pautas, sino por la cortedad ("tímidas alteraciones") que hizo improbable el despliegue de una renovación capaz de promover una ruptura para la creación de lo nuevo, para la apertura de un particular camino creativo. En consecuencia, la medida del real atraso se establece, no sólo por la apatía, el letargo o la dejadez propios, sino también por la subordinación y el acomodo a las pautas de otros. Y ya conocemos los resultados de ese camino: desarrollo servil, carencia de creatividad, independencia y crítica. Juan Acha dice que, si bien nuestra occidentalización nos impuso la duda, finalmente nos atrapan y obnubilan las persuasiones occidentales: "Como secuela, preferimos importar la letra de los cambios y no su espíritu, pues este incomoda a nuestra pereza intelectual" (1993: 17). Siguiendo esta idea, se puede entender por qué afirmo que el retraso, ese verdadero "quedarse atrás", no acontece en relación a un otro, sino respecto a nosotros mismos.

No obstante lo anterior, escudriñar la razón del retardo en la captura de las pautas modernas puede ayudarnos a entender la disposición, no siempre invo- 
luntaria, que se pudo tener frente a lo establecido como "progreso" artístico. Se trata de lo que Oyarzún señala sobre el arte chileno, aplicable también al latinoamericano:

La constante de un dato externo (el dato internacional), que entra decisivamente en la definición de un arte modernizado entre nosotros, ya da sobrada razón para que resulte fallido un relato armado desde la presunta evolución interna de las formas. / (...) en el corpus de cada una de esas modernizaciones, [se imprime indeleblemente el] destiempo por el cual ninguna de éstas está al día de lo que declara o en el lugar en que se anuncia (2015: 217).

En otras palabras, la "importación de la letra de los cambios" fue frecuentemente hecha en tiempos posteriores al momento en que se gestaron originalmente los movimientos. Y si bien el tiempo de retardo es parte del proceso de asimilación de los recursos, lo que deja en evidencia a las modernizaciones artísticas es la condición de la letra a importar. Una característica común que tenían esas importaciones es que, al momento de ser adoptadas, ya eran letra consagrada. Por tanto, esta demora podría acusar, no pereza intelectual como dice Acha, sino que una propensión al cálculo que combina tanto la aversión al riesgo como la necesidad de validación. En ese sentido, su retardo, a diferencia del retraso propio -como en la pintura paraguaya-, podría estar indicando un acomodo astuto. Esto es, si las modernizaciones no asimilaron los aportes de las vanguardias en su tiempo de estallido, se puede deducir que su actualización andaba en busca de una modernización asegurada, sin contratiempos, al menos en la adopción de sus postulados. Entonces, predecible es que sus pasos se dirigieran a alcanzar modelos ya aceptados, es decir, cánones pertenecientes al centro del centro. Y claro, ya que toma tiempo que una vanguardia se haga parte de lo consagrado, es probable que existiera una demora en su importación.

Es evidente que las modernizaciones artísticas no buscaban un referente que perteneciera a la periferia, ni siquiera a la de la periferia del centro, es decir a la vanguardia naciente, disidente y subversiva. Con el complejo que cargaba, el arte latinoamericano no podía ser parte de otra periferia, aun cuando esta fuera del centro mismo. Esto porque, en el fondo, lo que las modernizaciones buscan es ser parte de aquello que es reconocido oficialmente como "progreso".

En este sentido, el retardo es en parte proporcional, no a la incapacidad de la puesta al día, sino al tiempo que la oficialidad se toma para absorber las nuevas tendencias. De hecho, gracias a que el reconocimiento de una tendencia vanguardista ha sido cada vez más corto (y efervescente como la moda), y gracias a la activación e instantaneidad de los medios de difusión, es que prácticamente ya no se producen retardos en las actualizaciones de Latinoamérica. Basta con que las propuestas vanguardistas sean reconocidas y divulgadas, para que las condiciones de la importación y la consiguiente inscripción sean óptimas. Prueba de su finalidad es que, habiéndose superado el retardo, las ansias de validación persisten, haciéndose visible en aquellos artistas que se dejan absorber por el mainstream internacional del arte contemporáneo. 
Con todo, la idea del acomodo, de falta de riesgo o de arrojo de las modernizaciones artísticas en Latinoamérica, no se dirige a desconocer las grandes luchas emprendidas por artistas y teóricos al divulgar los nuevos códigos del arte. Cada una de ellas constituyó grandes proezas al enfrentarse a la incomprensión, al rechazo o a la obstinación conservadora. No obstante, es necesario preguntarse si estas hazañas de actualización hubiesen sido dadas de no contar con el respaldo de la oficialidad artística euro-estadounidense. Claro, porque por mucha incomprensión, reparos o afrentas, siempre pudieron afirmarse en los juicios de autoridad que instruían sobre las pautas de progreso de turno en el arte.

Esta observación se puede apreciar, por ejemplo, en las palabras del crítico chileno -asociado al Grupo Montparnasse- Jean Emar, cuando, en 1924, refuta la crítica de Daniel de la Vega argumentando que ignora todo cuanto se debe saber sobre arte nuevo:

es casi un deber para todo crítico echar una mirada al "saco" del Arte Nuevo antes de hablar de él y de condenarlo a ciegas. / Dentro de ese saco, está Paul Cézanne, está Pablo Picasso, está André Derain, en pintura; están en letras Guillaume Apollinaire, Marcel Proust, Pierre Mac-Orlan, Jean Cocteau, etc. (Emar en Lizama, 1992: 83).

Todo esto apoyado por publicaciones que daban cuenta de cierto respaldo internacional. En una entrevista al Encargado de Negocios de Francia en Chile, Emar deja en claro quienes son los "avanzados" en el arte local. Henri Hoppenot señala:

Pasé en la Exposición del Grupo Montparnasse los mejores momentos de Arte que he vivido desde mi llegada a Chile (...) / Ese Grupo se halla en comunión con todos los artistas que en París, en Berlín, en Barcelona, en Nueva York se han evadido de las disciplinas muertas y de la tutela de los falsos maestros, y cuyos esfuerzos reunidos han alcanzado ya, por todas partes la aprobación del público. Sí; es necesario que sus compatriotas sepan que son ustedes los que representan el Arte VIVO (Hoppenot en Lizama, 1992: 89).

A esto me refiero cuando señalo que divulgar los paradigmas oficializados como modernos no basta para serlo. Recordemos que durante los años veinte y treinta el cubismo, el futurismo, el expresionismo y otros ismos triunfaban obteniendo el reconocimiento internacional. Estos ismos se habían convertido en productos de una suerte de oficialidad de la vanguardia, es decir, en vanguardias que, paradojalmente desde esta perspectiva, comenzaban a dejar de ser, operativamente hablando, modernas; justamente por acomodarse dentro de lo establecido, entiéndase: regulación, convención u oficialidad emanada de una autoridad artística. Es importante insistir en el hecho de que los modernismos siempre han ocupado el lugar del outsider, de aquel que no necesita ni tutela ni respaldo para edificarse.

El mismo Ticio Escobar advierte que una modernidad periférica, aquella que observa cada una de las etapas de las vanguardias, termina desvirtuando el sentido de la primera, ya que esta secuencia no es capaz de cumplir con las grandes misiones modernas: 
Al ser trasplantado y retrasplantado, y al serlo en suelos ajenos, este esquema sufre alteraciones importantes. Pero los cambios más profundos no derivan tanto de las readaptaciones requeridas por las particularidades de un medio específico como del trabajo de apropiación y desmontaje practicado en las regiones subalternas. Reproducidos (en contra del ideal de originalidad que está en su principio), diferidos y amortiguados (más allá de sus proclamas de ruptura y de actualización permanente), convertidos en recurso personal (a contrapelo de su original vocación colectiva), tanto los principios de las vanguardias como sus estrategias terminan profundamente adulterados (2004: 15).

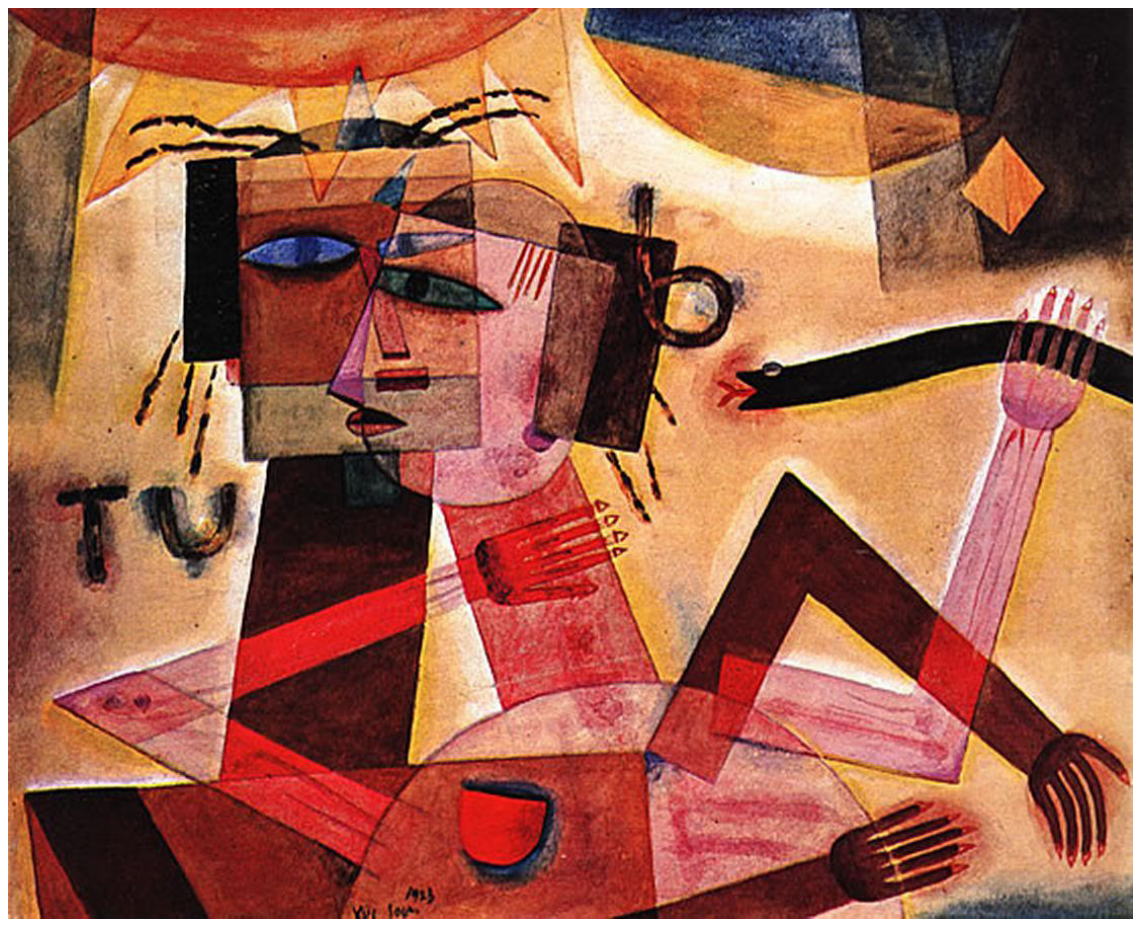

Figura 1. Xul Solar (1923), "Tú y yo".

Con todo, la alteración de principios y estrategias dadas no necesariamente merma lo moderno, de hecho, es la transformación la condición necesaria para lo moderno en tanto nuevo. En consecuencia, este no sería un punto de juicio. Sin embargo, lo que se destaca en las palabras de Escobar son los conceptos que aluden implícitamente a las operaciones utilizadas para conseguir una inscripción con el argumento de la "modernidad periférica". Estas actualizaciones, que observan cada una de las etapas de las vanguardias, reproducen, difieren, rezagan y amortizan a sus referentes. Aquí, cabe la pregunta ¿por qué llamar a estas operaciones "modernas" si, en estricto rigor, "lo moderno" no admite la reproducción, el rezago ni el amortiguamiento? 
Es más, incluso cuando no ha existido este letargo, se pretendió categorizar al arte local dentro de esta lógica. Por ejemplo, Beatriz Sarlo señaló a Xul Solar como el exponente de la cultura de la mezcla en el contexto de lo que llamó "modernidad periférica". La teórica argentina planteó que, en sus pinturas, Solar "mezcla modernidad europea y diferencia rioplatense, aceleración y angustia, tradicionalismo y espíritu renovador; criollismo y vanguardia" (2003: 15). Sin embargo, en el sentido de este análisis, el mérito de Solar no se encontraría en mezclar o incorporar varias "sustancias" a su obra, ni tampoco en diferir, rezagar o amortizar a sus referentes, sino en sostener la tensión entre estos dos mundos; rasgo propio de su contemporaneidad $^{6}$. Lo moderno de su propuesta se funda, primero, en el deseo motor de estar abierto a su realidad: simultáneamente moderna y tradicional. Y, segundo, en el hecho de que si bien no ignora el sedimento de revoluciones dadas -en especial del expresionismo-, su propuesta supera con creces las filiaciones referenciales. Solar, sin lugar a dudas, abre su propio camino modernista.

Otro ejemplo es el de Diana Wechsler quien, siguiendo el curso teórico de Beatriz Sarlo, definió la modernidad periférica de la siguiente manera:

Periférica, en el sentido de no hegemónica, receptora -aunque no pasiva- de los cambios producidos en los centros como París, Roma o Berlín. Ecléctica, ya que representa lenguajes que son síntesis a la vez que combinación peculiar de elementos de distinta procedencia y tradición cultural. Moderada, porque tiende a fisurar, a filtrar más que a quebrar. Constructiva, porque tiende a instituir más que a destruir espacios (1999: 292).

Vuelvo a preguntar entonces, ¿se puede llamar moderna a una propuesta receptora, sintética y moderada? A mi parecer, esta descripción estuvo lejos de ajustarse a un concepto que es tal, justamente por no ser ni receptor ni sintético ni moderado. Es cierto que la autocrítica nos enfrenta a la herida de la vergüenza, pero también puede conducirnos a la acción. Todo lo contrario, si por rehuir el vergonzoso papel del reproductor, ideamos el rol del traductor y/o tergiversador, lo que hacemos no es otra cosa que opacar nuestras propuestas y reforzar al referente jerarquizado.

Es importante recalcar esto: en términos culturales, no existen culturas atrasadas o periféricas. A lo más, existen culturas recesivas, con menor visibilidad, pero no por eso pobres en sus recursos. Al calificar de "recesiva" a la cultura latinoamericana, consigo alejarme de terminologías que involucren una asimetría menoscabadora. Con frecuencia, lo contrapuesto a lo hegemónico es entendido como lo subordinado, lo bajo o lo dependiente. Es decir, no se asume su contraparte como un otro "no dominante", sino que se lo interpreta como un otro necesariamente sometido e inferior. Por el contrario, el concepto de "cultura recesiva" que pro-

6. Durante la primera mitad de siglo XX, Latinoamérica atraviesa por un proceso donde las tensiones culturales oscilan fuertemente entre la necesidad de exponer una singularidad local y el intento de generar un vínculo con el mundo. Todas ellas son respuestas a las modernizaciones y a las profundas transformaciones sociales que se forjan. 
pongo, remite -al igual que en genética- no a una condición de inferioridad, sino simplemente a culturas que no se hacen visiblemente protagonistas en el cuerpo cultural, en este caso, occidental. Por cierto, este concepto admite que es otra la cultura que ostenta el poder o el control del capital simbólico, pero en ningún caso asume con esto un valor inferior como cultura. Lo recesivo, por tanto, no hace referencia a la inferioridad, sino al hecho simplemente político de ser una cultura no hegemónica. Desde esta perspectiva, y en comparación a lo que ha ofrecido el paradigma periférico-traductor, el horizonte de nuestros recursos y posibilidades culturales, ciertamente, se hace más amplio.

\section{Diferencia. Francisco Brugnoli: ¿un arte pop?}

Otra apreciación recurrente en la historia y teoría del arte latinoamericano fue la incomprensión de ese específico camino de realización de la modernidad artística latinoamericana. La invisibilización de sus características particulares a fin de poder acoplarse a los programas centrales, fue recurrente. José Luis Falconi es claro en criticar la homogenización y reducción de características particulares en favor de programas que no tiene nada que ver con Latinoamérica:

La tentativa de producir historiografía latinoamericana en este contexto es perniciosa porque deja a la región atascada en el atraso. Así como fue errado poner todos los intereses de Latinoamérica en el campo de la "irreducible otredad", igualmente es equivocado e ingenuo construir una historia acerca de nosotros mismos que simplemente enfatice similitudes y continuidades con la civilización occidental (131: 2014).

Y no sólo es equivocado e ingenuo, sino que también violento. Con frecuencia, la teoría del arte latinoamericano ha recluido las propuestas locales en casilleros restringidos, inhibiendo su desarrollo. A modo de ejemplo, veamos el caso del arte pop en Chile. Preguntémonos si verdaderamente fue posible instalar un pop art en un territorio donde no existía una sociedad de consumo masificada. Donde la pobreza, la inequidad y la segregación hacía lejana la posibilidad de ajustarse a los conceptos propagados por las celebridades de Hollywood, por la producción en serie, la publicidad y sus objetos de deseo. Indudablemente, esas trazas pertenecen a otro mapa. Pero claro, siempre está disponible la opción de hacer una versión local de este modelo cultural. Podemos torcer los discursos haciendo destacar los procedimientos que manipulan historietas locales, que readapten recursos publicitarios, cuestionen situaciones del todo ajenas o enaltezcan una serie de objetos a los que pocos tienen acceso. Discurso que incluso puede llegar a convencer a los propios artistas de llenarse de alegría, de moda, de colorido y, sobre todo, para adscribirse a las rupturas artísticas emprendidas por otros. Aunque también pudimos decir: "paso, nuestra realidad está en otra cosa. Pongámosle su propio término".

En los años sesenta y setenta en el Cono Sur, antes de los golpes militares, llevar el arte al espacio de todos tenía un sentido particular. Fueron tiempos mundiales 
y locales de grandes transformaciones y conflictos, como la Revolución Cubana, la invasión estadounidense de Santo Domingo, las protestas laborales y estudiantiles del mayo francés, el reconocimiento y la integración de los sectores excluidos en Latinoamérica, la reforma universitaria en Chile, por nombrar algunos. En el arte regional, además de explorar nuevas formas experimentales, se dio un fuerte valor a la relación del artista con la sociedad. El imperativo no era masificar la cultura, sino democratizarla, hacerla accesible a todos.

Y si bien esta modernidad artística dada, el pop art, pudo ser un detonador para hacer reflexionar a los artistas locales sobre qué es lo popular en nuestra tierra, cómo se conjugan lo masificado con la cultura del pueblo, cómo se disimula/maquilla la pobreza o cómo persiste la estética de la reparación en nuestra idiosincrasia, etc., evidentemente sus respuestas poco tuvieron que ver con la cultura de lo desechable.

Pablo Oyarzún describe la semántica implícita en las obras que trabajan con el objeto desechable que, en nuestro contexto, nunca es desechado:

Es preciso atender aquí el carácter de que se inviste el trabajo con los deshechos en un medio donde los remanentes de la industria del plástico y de los envases-que, aun inútiles siguen adornados por el prestigio de la novedad de sus materiales y de sus formas- también se vuelven cosas atesorables, suerte de estéril capital museológico popular (2015: 227).

Entonces, dada la distancia con el pop art, los movimientos suscitados exigieron otros nombres. Nace así el "arte callampa", el "arte grasa", el "arte guachaca", el "arte chasquilla", el "arte guacho", el "popularte"... Es cierto, estos nombres nunca existieron, aun cuando había obras suficientes como para especular sobre el asunto y estimular nuevas perspectivas. Es que a los teóricos de esa época les fue más propicio ser receptivos con la terminología dada e interpretar al arte latinoamericano haciendo prevalecer el modelo imperante. De hecho, no sólo se trata de los teóricos de aquella época, sino también de los actuales (lo que demuestra la tendencia a lo largo del tiempo). En julio de 2016, se inaugura en el Museo de la Solidaridad Salvador Allende la muestra La emergencia del pop: irreverencia y caIle en Chile ${ }^{7}$, curada por Soledad García y Daniela Berger. La presentación señala:

Los artistas insatisfechos con los sesgos tradicionales del oficio y la formación artística buscaron lenguajes directos, rescatando raíces populares y locales mientras que las influencias extranjeras en los medios de masas, cobraban impacto, aceptación y rechazo (García y Berger, 2016).

Entonces, la pregunta que surge es ¿por qué llamar pop a una corriente chilena que, nutriéndose o no del pop art (aunque no faltaron los que sí se acoplaron a ella), tenía orientaciones únicas? ¿Por qué insistir con esta filiación? Hagamos el ejercicio imaginario de cambiar el nombre y la presentación de esta muestra:

7. Desde abril de 2016 a enero de 2017 también se expone en el Museo de la Solidaridad Salvador Allende la muestra "Pop Crítico", curada por Soledad García. 
Emergencia del Popularte. Irreverencia y calle en Chile, es una muestra que reúne a artistas de los años 1964 a 1973, destacados por su fuerte emergencia por cuestionar los procedimientos tradicionales y su formación artística. Para esto, buscaron lenguajes directos y críticos, que además dieran cuenta de las raíces populares y locales. Los objetos desechados, inútiles o desgastados, la publicidad intervenida o el cómic crítico, conforman un soporte vivencial acorde con la marginalidad y la inequidad sociales existentes...

La inauguración de nuevas categorías, conceptos y perspectivas puede, ayer u hoy, orientar y estimular al artista a reafirmar su particularidad, así como también alentar otras respuestas teóricas o artísticas, contrarias o complementarias.

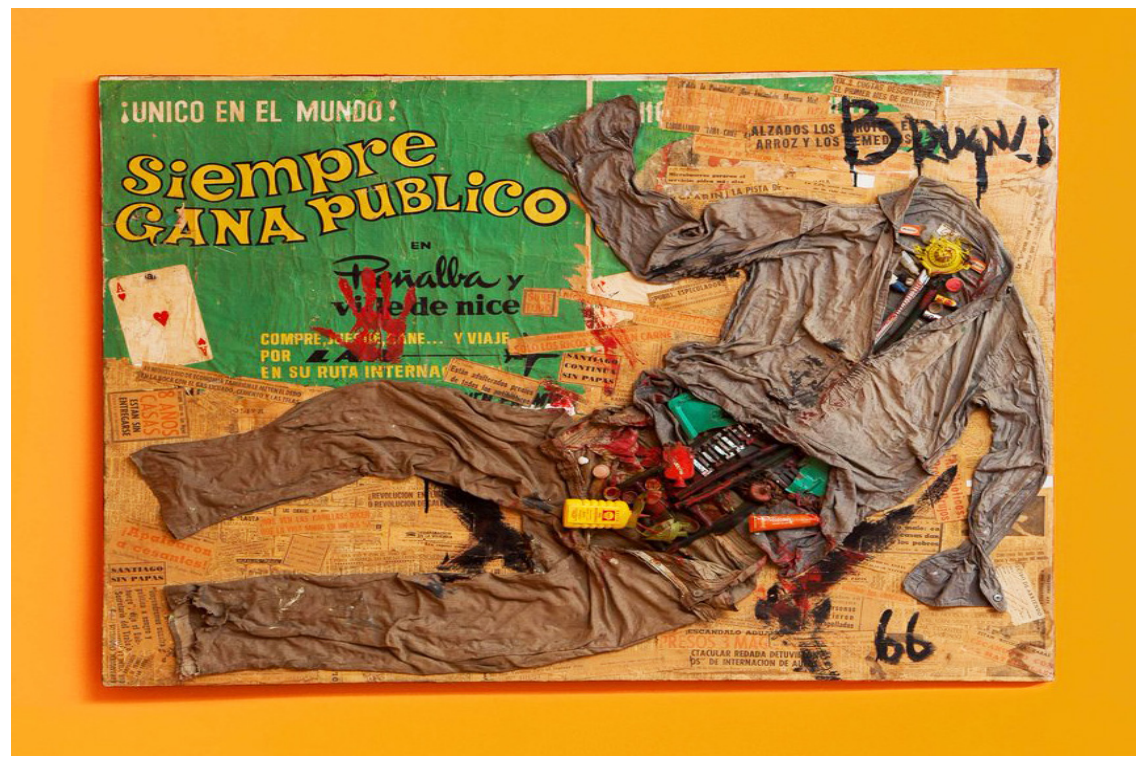

Figura 2. Francisco Brugnoli (1966), "Siempre gana público".

Lamentablemente, como decía antes, la recurrencia a que la historia y la teoría del arte latinoamericano se fundamenten siguiendo los trazos de la cultura dominante, es persistente. Por ejemplo, en relación a la obra de los sesenta del artista chileno Francisco Brugnoli, es común que se destaque un vínculo con Marcel Duchamp, Robert Rauschenberg o la influencia del arte povera. Siguiendo esta línea, no resulta sorprendente constatar que, actualmente, en el sitio web Artistas Visuales Chilenos del Museo Nacional de Bellas Artes, se describa en estos términos la biografía de Brugnoli: “En el año 1965 lideró el grupo Los Diablos cuyo quehacer estuvo asociado al Pop Art" (MNBA). Por otro lado, el sitio web El portal de Arte. $c l$, cuyo material está dedicado a la educación escolar, repite textualmente esta información. 
Incluso se ha llegado a afirmar, al más puro argumento pop, que la obra de Brugnoli problematizó la sociedad del consumo; asunto nada más alejado del enfoque del artista y de la realidad social imperante. En las palabras de Pablo Oyarzún se detecta esta disonancia:

[La obra de Brugnoli] apela a una sensibilidad de la vida cotidiana moderna. Y si esta cotidianidad se registra, al modo pop, a partir de la instancia del consumo, ello se hace estrictamente a través de la mediación de un consumo diferido y dependiente, y cruzado por las cargas reordenadoras de un imaginario popular. En este sentido, la producción que describimos trae consigo la primera consideración temática, la primera puesta en tela de juicio de lo "moderno" en el contexto del arte nacional: según ella, nuestra experiencia social cotidiana en su conjunto es develada como residuo de la modernidad (2015: 227).

La reflexión de Oyarzún da cuenta de dos aspectos relevantes. Primero, de una vinculación disonante con el pop, y, segundo, de una marginalidad en disputa con la modernización. Esta discrepancia se provoca porque las ideas que soportan al pop art no son las que impulsaron la obra de Brugnoli. ¿Cómo apelar a una experiencia de consumo cuando la modernización social y material no había llegado del todo a Chile? ¿Cómo hablar de consumo si el consumismo en el Chile de los sesenta en ningún caso fue un problema masificado y, de existir, sólo abarcaba una parte muy minoritaria de la población? ¿Cómo hablar de una cultura pop, si en Chile pesaba más la presencia de la cultura popular? Entonces, ¿ipor qué llamar pop a un arte que nunca fue pop art? De ahí la disonancia. Por lo tanto, si para orientarnos consideramos sus coordenadas, ciertamente la obra de Brugnoli se presentará o torpemente desencajada o patéticamente resistente: ambas posturas igualmente dependientes de su referente.

Ya se decía antes, el paradigma de la similitud, que se concibe como una continuación de la tradición europea, al basar la construcción de categorías que clasifican al arte latinoamericano según las formas estilísticas del centro, omite las características que definen y particularizan, en este caso, al arte chileno.

Los recursos y procedimientos empleados por Brugnoli: el pegoteo, el objeto ultra reutilizado, el enmascaramiento, el ornato saturado, la publicidad popular, las señales de la precariedad, etc., son, nada más ni nada menos, que los signos de su propio tiempo, de su contemporaneidad. Una propuesta que, desde su propia modernidad y mediante los recursos formales disponibles, puso en evidencia una modernización en conflicto con la precariedad social de su época. Hay que comprender que los materiales y procedimientos utilizados por este artista no fueron en absoluto ajenos. En los tiempos de las "poblaciones callampas" 8 todo material servía: nada era desecho, todo contribuía al collage de la vivienda. Valiéndose del sedimento de revoluciones artísticas anteriores, a Brugnoli sólo le bastó abrirse a su realidad para levantar su propio planteamiento.

8. Se denomina "población callampa" en Chile a los asentamientos informales que se establecían con la misma rapidez que las callampas en los jardines. Su construcción era sumamente precaria, realizada con recortes de materiales de construcción desechados. 
Siguiendo en parte lo que dice Oyarzún, estas obras ponen en tela de juicio, más que "lo moderno", los efectos de una desigual modernización. Esto es, el artista propone una respuesta modernista -ofrece una expresión artística propia, renueva los recursos, revisa las prácticas y la recepción artística, rompe con las tendencias obsoletas de manera libre y crítica, enuncia un ideario, etc.- que apunta a cuestionar las transformaciones y experiencias modernizantes del Chile de su tiempo. Este planteamiento es anticipadamente coincidente con la reflexión de Norbert Lechner, quien, más adelante, señala que en Latinoamérica es posible que se dé una modernización sin modernidad, ya que los costos económicos de la modernización merman los valores sociales y políticos modernos ${ }^{9}$.

Contrariamente, si se lee la obra de Brugnoli desde los paradigmas artísticos dados, lo habitual es que la interpretación omita o minimice esta perspectiva para poner hincapié en los argumentos de la ruta artística hegemónica, a saber, el cuestionamiento a la representación mediante el procedimiento del collage y el uso de objetos. En relación al collage, Brugnoli señala:

Entonces comenzamos a hacernos algunas preguntas, por ejemplo, ¿qué es lo que está afuera de esta escena? Y nos empezó a molestar el concepto de representación, del artista como representante de aspectos culturales, de los artistas míticos, etc., por lo que comenzamos a recoger cosas, imágenes y objetos incluso de caminatas por la calle San Diego y San Pablo. Así empezaron a aparecer estos collages que molestaron tanto y por el que alguna prensa nos llamó artistas pop. La verdad es que podría haber una relación, pero la gráfica que recogíamos era del restaurant que decía Hoy chacarero ${ }^{10}$ (Brugnoli en Díaz López, 2010, 10 de diciembre).

Es importante señalar que la hazaña del cuestionamiento de la representación y el uso del objeto en el arte ya habían sido inaugurados por otros artistas cincuenta años antes en Europa, por lo que en sí mismos y en términos modernos -lo nuevo, lo opuesto a "lo de ayer"-, no representaban ningún mérito, ni siquiera para los artistas pop euro-estadounidenses. Como dice Falconi, establecer similitudes con la cultura hegemónica sólo nos coloca en la posición del retraso. Contrariamente a lo que plantean los argumentos de la similitud, lo relevante de esta propuesta fue, precisamente, que el collage rescatara la gráfica popular del "Hoy chacarero", lo que, bajo la lógica democratizadora de la cultura, significaba llevar al espacio del arte el mundo menospreciado por nuestra alta cultura. O visto de otro modo, hace que la estética popular participe de un espacio tradicionalmente elitista. Esta disposición fue la que dio cuenta de su modernidad -ruptura e innovación-y en ella se alojó su mérito, no en el uso de revoluciones emprendidas por otros; aun cuando ellas hayan colaborado o participado en su práctica.

9. Norbert Lechner (1990) explica que la modernización se produciría preferentemente en el ámbito económico, abandonando el progreso en el plano práctico-moral de la sociedad. Es decir, se estaría quebrantando igualdad, derechos humanos, autorrealización, autonomía moral, etc., en pos del progreso técnico-material. Lechner se pregunta cómo las sociedades latinoamericanas podrían enfrentar los costos económicos de la modernización sin dejar de considerar los costos sociales.

10. El chacarero es un sándwich típico de la gastronomía chilena. 
El problema de no tomar en cuenta la realidad local, las especificidades productivas, históricas y sociales en las que están insertos los signos, materiales y procedimientos de las obras, no sólo produce una invisibilización de su valor, sino que, además, puede provocar reproches y quejas descontextualizadas. Por ejemplo, se le criticó mucho a Brugnoli (y él mismo se critica) la literalidad del mensaje de sus obras durante ese período. Claro, porque lo esperable -como continuación de la oficialidad artística- era que rompiera con las estructuras de significación para imponer un sentido múltiple y equívoco, como signo de un tiempo que padecía una irrevocable ausencia de sentido. Aunque no corresponde a la misma estética, este reproche recuerda la crítica inserta en la obra de Sigmar Polke Los seres superiores ordenan: ipintar de negro la esquina superior derecha! Entonces, siguiendo las premisas del sentido equívoco, se puede comprender por qué la transparencia de su mensaje fue evaluada como una falta imperdonable: quedaba fuera de las pautas dadas por los "seres superiores". El problema es que nuestra realidad no se movilizaba en ese sentido.

En el Chile de la época, así como en los procesos culturales y políticos de toda América Latina, fue imperativa la democratización de la cultura. La inequidad social podía compensarse, en parte, con la igualdad cultural. Acortar las distancias entre el arte elitista institucionalizado (museo, academia, mercado), el arte popular y la cultura de masas, se constituyó como un campo simbólico cargado de esfuerzos y ansias por incorporar al rezagado y a lo rezagado. En palabras de Oyarzún, se trataba de:

(...) necesidades expresivas de una experiencia social e histórica de los grupos subalternos, el interés por las formas "espontáneas" en que esa experiencia se plasma cotidianamente, $y$ los ensayos encaminados a redefinir las relaciones que establece el productor cultural y su acción con la sociedad, [fueron] ensayos de replantear, pues, su misión social (2015: 233-234).

Por tanto, si ponemos la obra de Brugnoli en su contexto y analizamos las condiciones de rebeldía de su propuesta, claramente la transparencia de su mensaje no sería una falencia. Esto porque su acto revolucionario no se alojaba en la trama de significación, sino que en el campo mismo de la cultura. La ruptura de la burbuja del arte elitista mediante procedimientos, materiales y signos agitadores, era su objetivo. El arte de la época, por su anhelo de democratización, quería llegar a todos, explicitar su reflexión, empaparse de los objetos cotidianos, de sus modos de construcción, de su política específica, de su anhelo de igualdad. Aun a riesgo de construir una propuesta desbordada de honestidad.

Considerar las pautas del arte hegemónico sin analizar las condiciones contextuales de las obras puede hacernos configurar una desacertada percepción de anomalía. Cierto es que, en el "juego de la similitud" (o de la imitación), catalogamos como torpe o inepto al que no logra seguir fielmente los movimientos. Sin embargo, no siempre estamos jugando a ese juego (al del monito mayor). Hay ocasiones en que la cultura recesiva simplemente está ejecutando sus propias agitaciones. 


\section{A modo de conclusión}

Como pudimos constatar, existió (y existe aún) un inexorable condicionamiento en la categorización e interpretación de los programas del arte latinoamericano a partir de las fases, metas y significaciones de progreso del arte hegemónico. Como parte del objetivo central de este artículo, la discusión con los textos y el examen contextual de propuestas artísticas como, en particular, la de Francisco Brugnoli, permitió establecer la necesidad de realizar una constante revisión de nuestros productos y operaciones intelectuales/artísticas, tanto actuales como pasados. Esto porque, la idea de que, para entrar a la modernidad artística, todos debimos recorrer y cumplir con una serie de etapas y pautas, cumplir con "un proceso necesario", ha estado latente incluso en las evaluaciones de promotores de las especificidades del arte latinoamericano.

Esto no implica que la teoría no haya reconocido la alteración de los principios y estrategias del arte central como una operación válidamente moderna. Sin embargo, constatamos que en algunos casos el tenor de esta alteración nos conducía a operaciones que reproducen, difieren, rezagan y amortizan a sus referentes, es decir, a lineamientos no coherentes con el temple de la modernidad artística. Por lo tanto, si por rehuir el vergonzoso papel del reproductor nos identificamos con el papel del traductor, lo que hacemos es, por un lado, justificar a aquellas propuestas que no llegaron a ser más que versiones latinoamericanas del arte central o, peor aún, mermar la potencia de aquellas propuestas que superaron con creces las filiaciones referenciales.

Este problema dio cuenta de que no estuvimos libres del retraso, de ese quedarse atrás propio. Con el mismo rigor se afirma que no es el desacoplamiento de las fases, metas y significaciones de progreso artístico lo que nos retrasa, pues hay que asumir que sí existen factores que marcan nuestro estancamiento. Tanto la apatía como el acatamiento y el acomodo a las pautas de otros contribuyen a esa falta. Por tanto, habrá que examinar, también hoy, cuándo "el abuso de la batalla digestiva", como la llamó Mosquera, sirvió para explicar, justificar y facilitar la apropiación en el contexto de esta desigual occidentalidad de la que somos parte.

Con todo, hay que reconocer que ha sido la invisibilización de las características particulares (de la realidad local, de las especificidades productivas, históricas y sociales en las que están insertas las obras), lo que ha provocado, mayormente, la incomprensión de las especificidades artísticas latinoamericanas. Así, de la misma forma que es erróneo autocomprendernos desde el papel del traductor, es sesgado crear una imagen, narración o historia de nosotros mismos estableciendo similitudes con el centro. Por muy vergonzoso que sea, hay que admitir que aún existe en nuestra cultura un persistente acoplamiento, no sólo involuntario, sino también intencional y estratégico a las pautas hegemónicas. La propensión al cálculo, que combina tanto la aversión al riesgo como la necesidad de validación, 
buscó -y busca también hoy- parámetros de progreso avalados por la autoridad. Este ejercicio nos hace creer que los juicios de autoridad nos fortifican, lo que se extiende también a la práctica artística. Constreñir las obras a un modelo dado, evidentemente, restringe e inhibe los desarrollos creativos y teóricos de otras y múltiples propuestas.

Sólo basta con revisar la definición que da Berman sobre modernismo para comprender la necesidad de establecer nuestros propios parámetros: manifestaciones culturales y artísticas que se vinculan con las experiencias y transformaciones de la modernidad. Por tanto, si la modernidad ha sido diferente en Latinoamérica, si ha sido más compleja, confusa o incluso distorsionada, a ojos de los cánones hegemónicos, resulta evidente pensar que las visiones de tales transformaciones, sus modernismos, sean paradójicos, extraños $\mathrm{o}$, a mi entender, simplemente distintos en virtud de su congruencia. Efectivamente muchos han sido así, claro que, a condición de ser justamente modernismos, es decir, manifestaciones de ideas, visiones o experiencias sobre las transformaciones de su modernidad. Por lo tanto, fundamental es preguntarse y evaluar constantemente cómo la dinámica de la propia historia fue configurando un camino específico de creación artística, en sus propios términos, por muy diferente que esto pueda haber sido expresado.

\section{Referencias}

Acha, J. (1993). Las culturas estéticas de América Latina. México: Universidad Nacional Autónoma de México.

Beriain, J. (2005). Modernidad: ¿una, ninguna o muchas? En: Modernidades en disputa. Barcelona: Anthropos.

Berman, M. (2011). Todo lo sólido se desvanece en el aire: la experiencia de la modernidad. México: Siglo XXI.

Castro-Gómez, S. (1998). Latinoamericanismo, modernidad, globalización. Prolegómenos a una crítica poscolonial de la razón. En: Castro-Gómez, S.; Mendieta, E.; eds. Teorías sin disciplina. Latinoamericanismo, postcolonialidad y globalización en debate. México: Porrúa, 5-30.

Díaz López, Isis (2010, 10 de diciembre). Francisco Brugnoli: "La universidad es el mejor espacio para reflexionar". Facultad de Artes de la Universidad de Chile (sitio web). Recuperado el 16 de septiembre 2015 de http://www.artes. uchile.cl/noticias/67987/francisco-brugnoli-la-universidad-es-un-espaciopara-reflexionar.

Eisenstadt, Shmuel (2013). América Latina y el problema de las múltiples modernidades. Revista Mexicana de Ciencias Políticas y Sociales, LVIII(218), 153164.

Eisenstadt, Shmuel (2000). Multiple modemities. Daedalus, Journal of the American Academy of Arts and Sciences, 129(1). Cambridge: MIT Press, 1-31. 
Escobar, T. (2004). Las otras modernidades. Notas sobre la modernidad artística en el cono sur: el caso paraguayo. Asunción: CAV/Museo del Barro, FONDEC.

Falconi, J.L. (2014). No Me Token: o, cómo asegurarnos de nunca perder el * por completo. Kaypunku, (1), 113-135.

García, S.; Berger, D. (2016). La emergencia del pop: Irreverencia y calle en Chile. MSSA (sitio web). Recuperado el 25 de julio 2016 de https://mssa.cl/exposicion/la-emergencia-del-pop-irreverencias-y-calle-en-chile/.

Jürgen, H. (1989). El discurso filosófico de la modernidad. Madrid: Taurus.

Lechner, N. (1990). ¿Son compatibles modernidad y modernización? El desafío de la democracia latinoamericana. Documento de Trabajo FLACSO, (440). Recuperado el 23 de agosto 2016 de http://flacsochile.org/biblioteca/pub/ memoria/1990/000204.pdf.

Lizama, P. ed. (1992). Escritores de Chile II. Recopilación, Selección e Introducción. A. Jean Emar: Escritos de Arte (1923-1925). Santiago de Chile: Universitaria.

Mosquera, Gerardo (2009). Contra el arte Latinoamericano. Conferencia en el Centro Cultural España Córdoba. Recuperado el 18 de mayo de 2014 de http://ccemx.org/archivovivo/archives/artwork/hipertextos/contraelarte.

MSSA (2016). Exposición Pop crítico. Museo de la Solidaridad Salvador Allende (sitio web). Recuperado el 25 de abril 2016 de http://www.mssa.cl/exposicion/pop-critico/.

MNBA (SF). Francisco Brugnoli. Artistas Visuales Chilenos (sitio web). Recuperado el 15 de abril 2017 de http://www.artistasvisualeschilenos.cl/658/w3article-40348.html.

Oyarzún, O. (2001). La desazón de lo moderno: Problemas de la modernidad. Santiago de Chile: Cuarto Propio/Arcis.

Paz, O. (1990). La búsqueda del presente. Inti: Revista de literatura hispánica (32). Recuperado el 27 de mayo 2015 de http://digitalcommons.providence. edu/inti/vol1/iss32/2.

Portal de Arte.cl (SF). Francisco Brugnoli. Portal de Arte (sitio web). Recuperado el 24 de abril de 2016 de http://www.portaldearte.cl/autores/brugnoli1.htm.

Rama, Ángel (2008). Transculturación narrativa en América Latina. Buenos Aires: El Andariego.

Sarlo, B. (2003). Una modernidad periférica: Buenos Aires 1920-1930. Buenos Aires: Nueva Visión.

Wechsler, D. (1999). Impacto y matices de una modernidad en los márgenes: artes plásticas entre 1920 y 1945. En José Emilio Burucúa, ed., Nueva Historia Argentina: Arte, Sociedad y Política. Buenos Aires: Sudamericana. 